\title{
Treatment failures of cefotaxime and latamoxef in meningitis caused by Enterobacter and Serratia spp.
}

\author{
Robert H. K. Eng, Charles E. Cherubin ${ }^{b}$, Jean-Claude Pechere ${ }^{c}$ and \\ Thomas R. Beam, Jr.d
}

'Infectious Disease Section. Medical Service. Veterans Administration Medical Center. East Orange, NJ 07019, and New Jersey Medical School/UMDNJ, Newark, New Jersey, U.S.A; 'bepartment of Medicine, Bayley Seton Hospital, Staten Island, New York 10304, U.S.A; 'Département de Microbiologie, Centre Médical Universitaire. Université de Genève, Genève $4 \mathrm{CH}-1211$, Switzerland: 'Infectious Disease Section. Veterans Administration Medical Center, Buffalo, NY and Department of Medicine, SUNY at Buffalo, NY 14215, U.S.A.

\begin{abstract}
Despite the apparent success of several new cephalosporins in the treatment of Gram-negative bacterial meningitis, four treatment failures with cefotaxime or latamoxef were encountered (two caused by Enterobacter and two by Serratia spp.). In-vitro parameters of susceptibility of these clinical isolates were compared with those of a meningeal Ent. cloacae isolate from a successfully treated patient. The MIC and MBC values, degrees of inoculum effect, and amounts of $\beta$-lactamase produced correlated poorly with the observed clinical outcome. However, the extent to which an isolate was killed by the cephalosporin used for treatment, in a 6 -h invitro incubation, showed good correlation. We suggest that such a test should be used to predict clinical outcome of therapy because the other parameters such as the MIC and MBC values are not sufficiently discriminatory.
\end{abstract}

\section{Introduction}

The treatment of Gram-negative bacterial meningitis with several of the newer cephalosporins (such as cefotaxime, ceftriaxone and latamoxef) has been highly successful and documented in an extensive literature (Cherubin et al., 1982; Corrado, Gombert \& Cherubin, 1982; Cherubin \& Eng, 1986). However, individual reports have begun to appear describing treatment failures (Bradsher, 1982; Eng et al., 1984a). Organisms responsible for failures have included susceptible strains of Escherichia coli, Klebsiella pneumoniae and Salmonella spp. An earlier study showed that the failures were possibly attributable to a lack of rapid bactericidal activity of the new cephalosporins against the individual isolates of the patients (Eng et al., 1984a). Whether such observations can be expanded to include other members of the Enterobacteriaceae is not known.

In four treatment failures (two Enterobacter and two Serratia species) the pathogens were available and were studied in vitro for killing activity of the cephalosporins employed during treatment. The results were compared with those from a successful

Correspondence: Dr Robert Eng, Medical Service (111), VA Medical Center, East Orange, NJ 07019, U.S.A. 
treatment of enterobacter meningitis. In addition, $\beta$-lactamase production in these and other control isolates was examined, to determine the importance of this in treatment failure.

\section{Materials and methods}

\section{Patients, bacterial isolates and antibiotics}

The cases of Gram-negative bacterial meningitis were cases seen by the authors or referred to them by other Infectious Disease physicians during the period 1978 to 1980 . Enterobacter cloacae EL 3513 was also included in the study. This organism was obtained from the blood of a patient and, in a rabbit model of meningitis, had been shown to be unresponsive to therapy by cefotaxime and latamoxef (Beam, 1983). A collection of nonmeningeal isolates of Ent. cloacae was also included for $\beta$-lactamase studies.

\section{Susceptibility testing}

The bacterial isolates were tested for susceptibility to antibiotics in three ways. First, the isolates were tested by macro-broth dilution method with an inoculum of $5 \times 10^{5} \mathrm{cfu} / \mathrm{ml}$ in $1 \mathrm{ml}$. Secondly, the method described by Eng, Smith \& Cherubin (1984b) was used to ascertain the effect of a large inoculum $\left(5 \times 10^{7} \mathrm{cfu} / \mathrm{ml}\right)$ on the susceptibility results. Thirdly, the method of washing the bacteria free of antibiotic before subculture was used to eliminate the antibiotic carry-over effect (Eng et al., 1984a).

\section{Killing kinetics}

Killing curves were generated by exposing $5 \times 10^{5}$ or $5 \times 10^{7} \mathrm{cfu} / \mathrm{ml}$ bacteria in tubes containing $5 \mathrm{ml}$ Mueller-Hinton broth and multiples of the MICs of the test antibiotics, as described by Eng et al. (1984a).

\section{$\beta$-Lactamase studies}

Bacteria were grown at $37^{\circ} \mathrm{C}$ in tryptic soy broth (Difco, Detroit, $\mathrm{MI}$ ), with shaking at $300 \mathrm{rpm}$. Organisms were collected by centrifugation in late logarithmic phase, after 2-3 h growth, $\left(1.2 \pm 0.4 \times 10^{9} \mathrm{cfu} / \mathrm{ml}\right)$, and washed twice in $0.1 \mathrm{M}$ saline. Bacteria $(1 \mathrm{ml}$ pellet, or approximately $1 \mathrm{~g}$ wet weight) were resuspended in $5 \mathrm{ml}$ saline and disrupted by sonic treatment (Artek Sonic 300 at $60 \mathrm{~W}$ ) by two $3.5 \mathrm{~min}$ bursts. The preparation was maintained on ice during sonication. Cell debris was removed by centrifugation at $48,000 \mathrm{~g}$ for $20 \mathrm{~min}$ at $4^{\circ} \mathrm{C}$ and supernatants were decanted. $\beta$-Lactamase activity in the crude extract was quantified using a spectrophotometric assay at $483 \mathrm{~nm}$ in $0.1 \mathrm{M}$ phosphate buffer, pH 7.0 (Ultraspec 4050, LKB produkter AG, Broma, Sweden, coupled with an Apple IIc microcomputer) with nitrocefin (100 $\mu \mathrm{M}$ final concentration) as substrate. $\beta$-Lactamase activities were standardized per $\mathrm{mg}$ of protein (BCA protein assay Kontron, Zurich, Switzerland). The amount of $\beta$-lactamase produced by a strain was given as the arithmetic mean of at least three completely independent determinations. 
$\beta$-Lactamase induction was assessed using an adaptation of the method of Gootz \& Sanders (1983), with cefoxitin, $10 \mathrm{mg} / 1$ final concentration, as inducer. Controls, without cefoxitin, were run simultaneously. Kinetic constants, $K_{m}$ and $V_{\max }$, were determined spectrophotometrically at $260 \mathrm{~nm}$ and $37^{\circ} \mathrm{C}$ after partial purification of the crude extract on Sephacryl S 200 in $0.1 \mathrm{M}$ Tris- $\mathrm{HCl}$ buffer $\left(\mathrm{pH} \mathrm{7.5)}\right.$ at $4^{\circ} \mathrm{C}$. Cephaloridine was used as substrate, at concentrations varying from 0.01 to $0.2 \mathrm{mmol}$. $\mathrm{K}_{\mathrm{m}}$ and $\mathrm{V}_{\max }$ values were estimated from a least-squares fit to a Lineweaver-Burk plot.

\section{Frequency of resistant clones}

The frequency of resistant clones existing within the bacterial population before exposure to $\beta$-lactam agents was estimated by enumerating the cfu on Mueller Hinton agar containing cefotaxime at 32 times the MIC. The starting inoculum size was 1.0 to $2.0 \times 10^{8} \mathrm{cfu}$ and the antibiotic agar plates were incubated for $24 \mathrm{~h}$ at $37^{\circ} \mathrm{C}$.

\section{Case studies}

\section{Case I}

This case has been previously reported by Corrado et al. (1982) and only the details of therapy are summarized here. A 31 year-old man developed meningitis several days after head trauma. Gram stain of his CSF revealed numerous Gram-negative bacteria. He received $12 \mathrm{~g}$ cefotaxime per day. The organism was identified as Ent.aerogenes and the MIC of cefotaxime was $0.06 \mathrm{mg} / \mathrm{l}$ by microdilution and $0.3 \mathrm{mg} / \mathrm{l}$ by macrobroth dilution. The CFS cefotaxime levels ranged from 4.1 to $11.5 \mathrm{mg} / \mathrm{l}$. The organism persisted in the CSF during therapy and appeared on Gram stain as filamentous forms. On days 2 and 3 of therapy, the same organism was isolated, with much higher MICs and MBCs of both cefotaxime and latamoxef $(0.3-2.5 \mathrm{mg} / \mathrm{l})$. This necessitated the addition of gentamicin $5 \mathrm{mg} / \mathrm{kg} /$ day intravenously and $8 \mathrm{mg} /$ day intrathecally, plus carbenicillin $500 \mathrm{mg} / \mathrm{kg} /$ day intravenously. The patient did not respond and died.

\section{Case 2}

A 57 year-old man developed Ent. cloacae meningitis 11 days after craniotomy for a left cerebral haematoma. Latamoxef was administered as initial therapy $(12 \mathrm{~g}$ day). The initial MIC and $\mathrm{MBC}$ of the isolate were 0.3 and $4.8 \mathrm{mg} / \mathrm{l}$, respectively, of latamoxef and 0.8 and $1.5 \mathrm{mg} / \mathrm{l}$, respectively, of cefotaxime. Repeat lumbar puncture $48 \mathrm{~h}$ later showed continued presence of the organism on Gram stain and cultures yielded a more resistant strain. Cefotaxime was substituted for latamoxef at the same dose. However, subsequent CSF bactericidal assays revealed no apparent killing activity for the latter isolates. The resistant strain had MIC and MBC of $10.0 \mathrm{mg} / \mathrm{l}$ for both antibiotics. Latamoxef was readministered along with $5 \mathrm{mg}$ /day gentamicin intrathecally. The patient recovered after 14 days of combined therapy.

\section{Case 3}

A 32 year-old man was admitted following a motorcycle accident. CT scan showed haemorrhage into the left maxillary sinus, and an intraventricular pressure monitoring 
device was inserted. On the fifth day, he developed deep coma and a temperature of $104^{\circ} \mathrm{F}$. Lumbar puncture yielded CSF with 20 polymorphonuclear cells and $332 \mathrm{RBC} / \mathrm{mm}^{3}$. Protein was $48 \mathrm{mg} / \mathrm{dl}$ and glucose $72 \mathrm{mg} / \mathrm{dl}$. A moderate number of Gram-negative bacteria were seen per high power field, subsequently identified as Ent. cloacae. The MIC of ceftriaxone was $0.2 \mathrm{mg} / \mathrm{l}$. The patient was started on ceftriaxone at $2 \mathrm{~g} 8$ hourly.

The patient showed no clinical improvement for three days. Although the CSF was sterile at this time, the CSF leucocyte cell count had increased to $11,400 / \mathrm{mm}^{3}$, On day 8 of therapy, a repeat lumbar puncture showed fluid with 103 WBC. The CSF ceftriaxone level was $7 \mathrm{mg} / \mathrm{l}$ and bactericidal activity was $1: 1024$. Progressive clinical improvement was noted between days 8 and 10 and the patient recovered without residua.

\section{Case 4}

A 57 year-old man had two surgical attempts at evacuation of a parietal haematoma from arteriovenous malformation. Five days after the second operation, he developed Ser. marcescens meningitis. He was treated initially with chloramphenicol, then with intrathecal amikacin for two days, then with amikacin and concurrent iv latamoxef for four days. His CSF remained culture-positive and he died. The initial isolate had MIC and $\mathrm{MBC}$ of 0.3 and $1.25 \mathrm{mg} / \mathrm{l}$ latamoxef, respectively.

\section{Case 5}

A 42 year-old developed Ser. marcescens meningitis after an evacuation of cerebral haematoma sustained in a car accident. He was treated initially with penicillin and chloramphenicol until the organism was identified. Intrathecal gentamicin and $12 \mathrm{~g}$ /day latamoxef were administered. CSF cultures remained positive after 14 days of therapy. A variety of other antibiotics, including new cephalosporins, were added, but the patient died.

\section{Laboratory results}

\section{Susceptibility results}

The MIC and MBC data are shown in Table I. The initial isolates from all the cases showed similar MICs and MBCs for all the $\beta$-lactam antibiotics tested. The isolate from the successfully treated case of Ent. cloacae meningitis (case 3) had MIC and MBC values indistinguishable from those of initial isolates from the failure cases caused by Enterobacter spp. (cases 1 and 2). The MBC values for the antibiotics used in therapy were $1.5 \mathrm{mg} / \mathrm{l}$ ceftriaxone for case 3 as against 2.5 and $1.2 \mathrm{mg} / \mathrm{l}$ of cefotaxime and latamoxef, respectively, for cases 1 and 2 . Subsequent isolates from the failure cases caused by Enterobacter spp. were far more resistant.

The MBC values were noted to depend on the methods used. The values obtained by the standard method are shown in Table I. These values of isolates from failure cases did not differ from the value of a successfully treated case. A comparison of washing versus not washing of the organisms on Millipore filters prior to subculture showed major differences in several antibiotic-bacteria combinations. A prime example of this 
Table I. Summary of antibiotic susceptibility of meningeal isolates

\begin{tabular}{|c|c|c|c|c|}
\hline Isolate & CTX & $\begin{array}{l}\text { MIC/MBC } \\
\text { LMX }\end{array}$ & CTR & IMP \\
\hline \multicolumn{5}{|l|}{ Case 1} \\
\hline \multicolumn{5}{|l|}{ Ent. aerogenes } \\
\hline initial & $\begin{array}{c}0.3 / 2 \cdot 5 \\
(8)\end{array}$ & $\begin{array}{c}0.3 / 2 \cdot 5 \\
(4)\end{array}$ & $\begin{array}{l}0.7 / 0.7 \\
(2)\end{array}$ & $\begin{array}{c}0.6 / 1 \cdot 2 \\
(4)\end{array}$ \\
\hline subsequent & $\begin{array}{c}40.0 />40.0 \\
(-)\end{array}$ & $\begin{array}{c}20 \cdot 0 / 20 \cdot 0 \\
(-)\end{array}$ & & $\begin{array}{c}0.3 / 0 \cdot 3 \\
\text { (1) }\end{array}$ \\
\hline \multicolumn{5}{|l|}{ Case 2} \\
\hline \multicolumn{5}{|l|}{ Ent. cloacae } \\
\hline initial & $\begin{array}{r}0 \cdot 6 / 1 \cdot 2 \\
(64)\end{array}$ & $\begin{array}{c}0 \cdot 3 / 5 \cdot 0 \\
(2)\end{array}$ & $\begin{array}{r}0 \cdot 7 / 6 \cdot 0 \\
(32)\end{array}$ & $\begin{array}{c}1 \cdot 2 / 2 \cdot 5 \\
(4)\end{array}$ \\
\hline subsequent & $\begin{array}{c}10 \cdot 0 />10.0 \\
(-)\end{array}$ & $\begin{array}{c}10.0 />10.0 \\
(-)\end{array}$ & $\begin{array}{c}10.0 />10.0 \\
(-)\end{array}$ & $\begin{array}{c}1 \cdot 2 / 2 \cdot 5 \\
(4)\end{array}$ \\
\hline $\begin{array}{l}\text { Case } 3 \\
\text { Ent. cloacae }\end{array}$ & $\begin{array}{c}0.3 / 1 \cdot 2 \\
(2)\end{array}$ & $\begin{array}{r}1 \cdot 2 / 2 \cdot 5 \\
(16)\end{array}$ & $\begin{array}{c}0 \cdot 2 / 1 \cdot 2 \\
(8)\end{array}$ & $\begin{array}{c}0 \cdot 6 / 2 \cdot 5 \\
(8)\end{array}$ \\
\hline Case 4 & $0.3 />20$ & $0 \cdot 3 / 1 \cdot 2$ & $0 \cdot 3 / 0 \cdot 3$ & $2 \cdot 5 / 5 \cdot 0$ \\
\hline Ser. marcescens & (64) & (2) & (2) & (4) \\
\hline Case 5 & $0 \cdot 6 / 1 \cdot 2$ & $0 \cdot 3 />5$ & $0.6 / 0 \cdot 6$ & $1 \cdot 2 / 2 \cdot 5$ \\
\hline Ser. marcescens & (64) & $(>32)$ & (4) & (2) \\
\hline EL 3513 & $0 \cdot 3 / 5 \cdot 0$ & $0 \cdot 3 / 0 \cdot 3$ & $1 \cdot 5 / 3 \cdot 0$ & $1 \cdot 5 / 1 \cdot 5$ \\
\hline Ent. cloacae & (2) & (8) & (8) & (2) \\
\hline
\end{tabular}

"CTX, Cefotaxime; LMX, latamoxef; CTR, ceftriaxone; IMP, imipenem.

Inoculum effect in parenthesis is expressed as the ratio of the MIC for $5 \times 10^{7} \mathrm{cfu} / \mathrm{ml}$ to the MIC for $5 \times 10^{3} \mathrm{cfu} / \mathrm{ml}$.

was the isolate from case 1 . After a $6 \mathrm{~h}$ exposure to cefotaxime at $32 \times \mathrm{MIC}$, there was less than a 1-log cfu reduction, but when the organisms were not washed free of the antibiotic a reading of a greater than 3-log reduction was recorded (Figure 1).

The MICs of cefotaxime, latamoxef and ceftriaxone for the isolates when the inoculum size was raised from $5 \times 10^{5}$ to $5 \times 10^{7}$ exhibited a two-fold to greater than

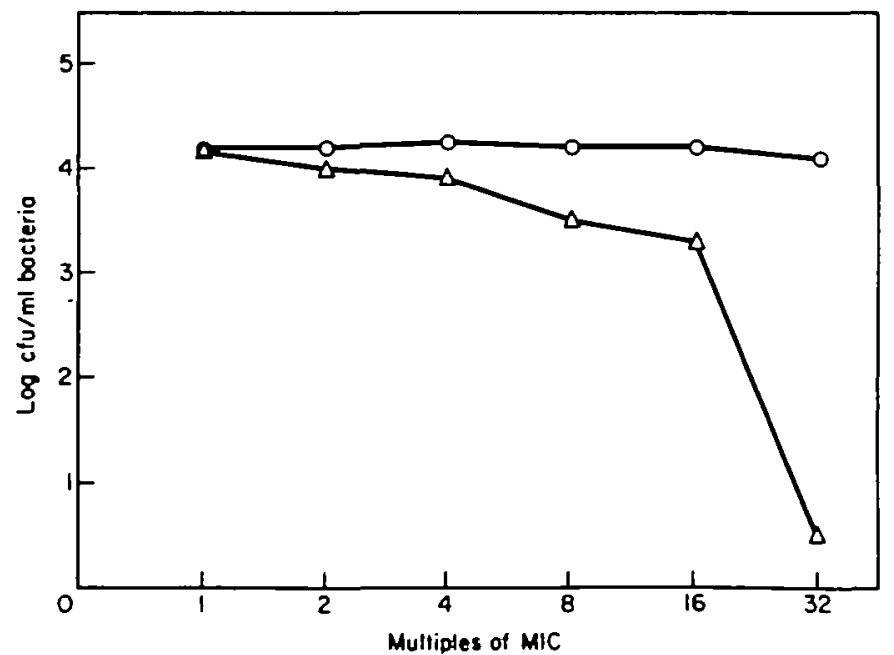

Flgare 1. Difference in $6 \mathrm{~h}$ bactericidal results when the organisms of the isolate from Case 1 were washed $(O)$ and unwashed $(\Delta)$ before subculture. 


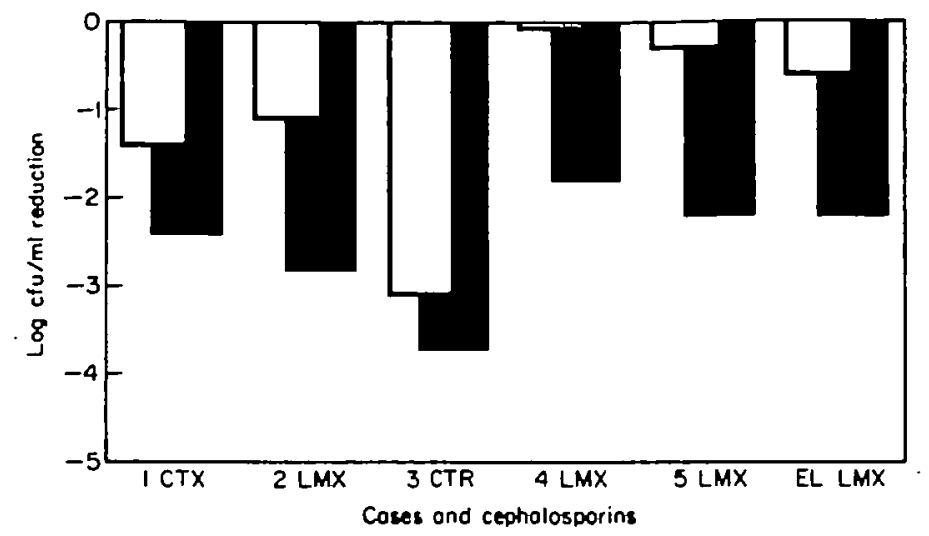

Figure 2. Number of bacteria killed in $6 \mathrm{~h}$ (open bars) and in $18 \mathrm{~h}$ (hatched bars) by $4 \times$ MIC of the cephalosporin used in treatment of the meningeal isolates or of EL 3513 (the meningitis animal model strain). Antibiotic abbreviations: see Table I.

32-fold increase. Imipenem did show a slight inoculum effect, but an inoculum effect of greater than eight-fold was not noted with this agent.

\section{Susceptibility of isolates to B-lactam killing}

The $\log$ decreases in $\mathrm{cfu} / \mathrm{ml}$ of each isolate when exposed to $4 \times \mathrm{MIC}$ of the antibiotic used in treatment are shown in Figure 2. The major distinguishing feature of the isolate from the successfully treated case (case 3 ) from the antibiotic failure cases was the amount of killing attained at $6 \mathrm{~h}$ of incubation. The isolate from case 3 attained a $3 \cdot 1 \mathrm{log}$ reduction in $\mathrm{cfu} / \mathrm{ml}$ in $6 \mathrm{~h}$ whereas other isolates showed a considerably smaller amount of killing.

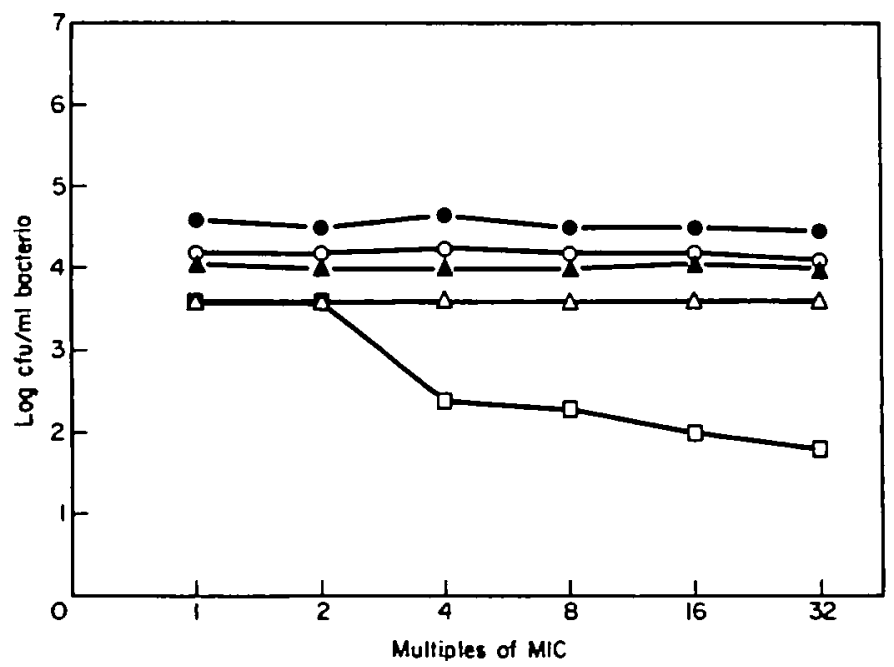

Figure 3. Concentration-dependent killing of meningeal isolates at $6 \mathrm{~h}$ by the cephalosporin used in treatment (case 1, cefotaxime, $O$; case 2, latamoxef, $\Delta$; case 3, ceftriaxone, $\square$; case 4, latamoxef, $\Delta$; and case 5 , latamoxef, $O$ ). The experiments were performed with washing of the bacteria free of antibiotics prior to quantitative subculture. 
When the antibiotic concentrations were increased in the killing kinetic studies, while antibiotic carry-over was eliminated by washing, isolates from cases 4 and 5 were totally resistant to killing by cefotaxime and latamoxef, as were the Enterobacter isolates recovered during therapy from cases 1 and 2 . In contrast, the isolate from the successfully treated case showed concentration-dependent killing (Figure 3).

\section{$\beta$-Lactamase production by the isolates}

$\beta$-Lactamase production before and after cefoxitin induction in these isolates is shown in Table II. For the Enterobacter isolates initially recovered from cases 1 and 2, the amount of $\beta$-lactamase produced was 0.02 and 0.1 units as compared to 0.02 unit from case 3 (success case). After induction by cefoxitin, the units of enzymes from the isolates of cases 1 and 2 were 0.3 and 0.2 , respectively as compared with 0.13 for case 3 . Hence the amount of $\beta$-lactamase produced by the organism with and without cefoxitin induction did not distinguish among the isolates with regard to success or failure during treatment with stable $\beta$-lactam antibiotics. The kinetic parameters, $\mathrm{K}_{\mathrm{m}}$ and $\mathrm{V}_{\max }$, were all characterized by low $\mathrm{K}_{\mathrm{m}}$, indicating a very high affinity of the $\beta$ -

Table I. Summary of $\beta$-lactamase studies

\begin{tabular}{|c|c|c|c|c|c|}
\hline Isolate & $\begin{array}{c}\beta \text {-Lactam } \\
\text { Without } \\
\text { induction" } \\
\text { (S.D.) }\end{array}$ & $\begin{array}{l}\text { activity } \\
\text { Induction } \\
\text { ratio }^{b}\end{array}$ & \multicolumn{2}{|c|}{ Kinetic values } & $\begin{array}{c}\text { Frequency of } \\
\text { clones resistant } \\
\text { to } \mathrm{CTX} \text { at } \\
32 \times \mathrm{MIC}\end{array}$ \\
\hline $\begin{array}{l}\text { Enterobacter } \\
\text { Case } 1\end{array}$ & & & . & & \\
\hline $\begin{array}{l}\text { first } \\
\text { second }\end{array}$ & $\begin{array}{l}0.02(0.01) \\
0.3(0.1)\end{array}$ & $\begin{array}{l}15 \\
4 \cdot 7\end{array}$ & $\begin{array}{l}0.4 \\
0.2\end{array}$ & $\begin{array}{r}1 \\
14\end{array}$ & $2 \times 10^{-6}$ \\
\hline Case 2 & & & & & \\
\hline $\begin{array}{l}\text { first } \\
\text { second }\end{array}$ & $\begin{array}{ll}0.1 & (0.01) \\
0.1 & (0.01)\end{array}$ & $\begin{array}{l}2 \\
7\end{array}$ & $\begin{array}{l}0.3 \\
0.3\end{array}$ & $\begin{array}{l}0.7 \\
19\end{array}$ & $1 \times 10^{-6}$ \\
\hline Case 3 & $0.02(0.01)$ & $6 \cdot 5$ & 0.9 & 0.8 & $<1 \times 10^{-8}$ \\
\hline EL 3513 & $0.02(0.01)$ & $9 \cdot 5$ & 0.2 & 11 & \\
\hline 1228 & $0.01(0.005)$ & 123 & 0.36 & 10 & \\
\hline 688 & $0.03(0.01)$ & 109 & 2.9 & 60 & \\
\hline 1483 & $1.51(0.2)$ & $4 \cdot 6$ & $0 \cdot 12$ & 10 & \\
\hline 1394 & $4.01(0.3)$ & 4 & ND & ND & \\
\hline 1201 & $4.79(0.3)$ & $1 \cdot 16$ & $0 \cdot 19$ & 11 & \\
\hline 692 & $0.02(0.005)$ & $10 \cdot 5$ & 0.73 & 0.7 & \\
\hline 362 & $0.01(0.005)$ & 4 & 0.37 & 0.08 & \\
\hline 1529 & $0.02(0.01)$ & 96 & ND & ND & \\
\hline 4207 & $0.01(0.005)$ & 15 & 0.2 & 0.5 & \\
\hline 66 & $0.01(0.005)$ & 28 & ND & ND & \\
\hline $\begin{array}{l}288 \\
\text { Serratia }\end{array}$ & $0.01(0.005)$ & 8 & 30 & $3 \cdot 0$ & \\
\hline $\begin{array}{l}\text { Case } 4 \\
\text { Case } 5\end{array}$ & $\begin{array}{l}0.15(0.01) \\
0.12(0.01)\end{array}$ & $\begin{array}{l}5 \cdot 3 \\
5 \cdot 8\end{array}$ & $\begin{array}{l}0.9 \\
0.3\end{array}$ & $\begin{array}{l}7 \cdot 3 \\
2 \cdot 0\end{array}$ & $\begin{array}{r}3 \times 10^{-7} \\
<1 \times 10^{-8}\end{array}$ \\
\hline
\end{tabular}

-Activity expressed in $\mu \mathrm{mol} / \mathrm{min} / \mathrm{mg}$ of protein.

"Ratio of activity following induetion with $10 \mathrm{mg} / \mathrm{l}$ cefoxitin to the uninduced level.

$\mathrm{K}_{\mathrm{m}}$ is expressed in $\mu \mathrm{mol}$ and $\mathrm{V}_{\max }$ in $\mu \mathrm{mol} / \mathrm{min} / \mathrm{mg}$ protein.

ND, Not determined. 
lactamase for the substrate. However, these parameters were similar for all the isolates studies, including the nonmeningeal isolates.

The organism isolated from patient 1 during treatment produced 15 times more $\beta$ lactamase than the pretreatment isolate. Also, with cefoxitin stimulation, the treatment isolate produced four times more $\beta$-lactamase than the pretreatment isolate. For case 2 , the second isolate showed a three fold increase in $\beta$-lactamase production in the presence of cefoxitin as compared to the pretreatment isolate. $\beta$-Lactamase induction by cefoxitin appeared to be more pronounced in those organisms isolated during therapy.

\section{Frequency of resistant clones}

The frequencies of clones resistant to 32 times the MIC for cefotaxime are shown in the last column of Table II. These frequencies ranged between less than $10^{-8}$ to $2 \times 10^{-6}$, with the lowest frequencies found in the organisms from cases 3 and 5 .

\section{Discussion}

Bacterial meningitis is a rapidly fatal disease and host defences in the CSF are limited. To a large extent, the patient is dependent upon the bactericidal activity of antibiotics to eradicate the organisms. Gram-negative organisms have presented a therapeutic problem because many older antibiotics were ineffective in vitro and in vivo. The use of the new cephalosporins appears to be associated with increased survival rates. However, cases of Gram-negative meningitis have been reported in which treatment with the new cephalosporins was associated with failure (Bradsher, 1982; Eng et al., 1984a).

The success of the new cephalosporins was initially attributed to potent activity as reflected in low MIC values. Closer examination of the susceptibility information with respect to clinical responses has shown that low MIC values are necessary, but by no means can be used as a universal predictors of treatment success of Esch. coli and $K$. pneumoniae meningitis. In these two species, it is unlikely that $\beta$-lactamases play a significant role in causing treatment failure. With Serratia and Enterobacter spp., however, treatment failures of nonmeningeal sites have been ascribed to the large amount of $\beta$-lactamases produced or induced. We have examined the in-vitro parameters of susceptibility to find the parameter that best predicts success of therapy. The amount of $\beta$-lactamases produced, and induced in Cases 1 and 2 did not differ greatly from that of the other Enterobacter isolates tested. Isolates recovered during therapy and which had become resistant showed markedly greater production of $\beta$ lactamase than the initial isolates from the same patient and, in general, the production rate is also greater than those isolates recovered from nonmeningeal sites. The amount of $\beta$-lactamase produced in the presence or absence of cefoxitin did not greatly differ between any of the groups of organisms. The frequency of resistant clones within the bacterial population of the pretreatment isolates was clearly different between the enterobacter failure and success cases. However, very low frequencies were also found among the isolates from the two serratia failure cases. The MIC values are clearly not sufficient in themselves to predict the success or failure of a treatment regimen, and the $\mathrm{MBC}$ results may be falsely low, unless the organisms are washed free of the test antibiotics before subculture. Yet, even with the addition of this washing step in the MBC methodology, the MBC values obtained from 18 to $24 \mathrm{~h}$ incubation 
in themselves were not sufficiently discriminatory to predict the success of therapy. Inoculum effect of the treatment antibiotic-isolate combinations also failed to discriminate between combinations that produced clinical success or failure.

On the other hand, the bactericidal effect at $6 \mathrm{~h}$ correlated well with clinical response. The isolate that showed a 3-log or more decrease following 6-h incubation with antibiotic concentrations up to $16 \times$ MIC was associated with success of therapy. Conversely, those bacterium-antibiotic combinations which did not produce a rapid decrease in cfu were associated with a poor clinical response. The $6 \mathrm{~h}$ bactericidal test is not difficult to perform and can be completed within one day in the microbiology laboratory; results can be available the next day. In fact, this test would require no more time for completion than the standard MBC test.

Our data are limited by the small number of cases we were able to collect. Our observation should be extended by infectious disease clinicians who treat such patients. If our conclusions can be upheld, bactericidal kinetics during the first $6 \mathrm{~h}$ of incubation could become a better test in the evaluation of antibiotics for treatment of Gramnegative bacterial meningitis.

\section{Acknowledgments}

We thank Dr David Droller, Dr Thomas R. Beam and Dr Myles Gombert for permission to report cases 2, 3 and 4, respectively. We also thank Frank Buccini for the technical assistance, and the Medical Media Production Service of East Orange VA Medical Center for the illustrations. This work was supported in part by the Veterans Administration and Fond National Suisse de la Recherche Scientifique (3.221.0.85).

\section{References}

Beam, T. R. (1983). Antibiotic failure in experimental meningitis. In Proceedings of 13th International Congress of Chemotherapy (Spitzy, K. H. \& Karrer, K., Eds), pp. 12-4. Verlag H. Egermann, Vienna.

Bush, K. \& Sykes, R. B. (1986) Methodology for study of $\beta$-lactamases. Antimicrobial Agents and Chemotherapy 30, 6-10.

Bradsher, R. W. (1982) Relapse of gram-negative bacillary meningitis after cefotaxime therapy. Journal of the American Medical Association 248, 1214-8.

Cherubin, C. E., Corrado, M. L., Nair, S. R., Gombert, M. E., Landesman, S. \& Humbert, G. (1982). Treatment of gram-negative bacillary meningitis: role of the new cephalosporin antibjotics. Reviews of Infectious Diseases 4, Suppl., S453-64.

Cherubin, C. E. \& Eng, R. H. K. (1986). Experience with the use of cefotaxime in the treatment of bacterial meningitis. American Journal of Medicine 80, 398-404.

Corrado, M. L., Gombert, M. E. \& Cherubin, C. E. (1982). Designing appropriate therapy in the treatment of gram-negative bacillary meningitis. Journal of the American Medical Association 248, 71-4.

Eng, R. H. K., Cherubin, C., Smith, S. M. \& Buccini, F. (1984a). Examination of gram-negative bacilli from meningitis patients who failed or relapsed on moxalactam therapy. Antimicrobial Agents and Chemotherapy 26, 850-6.

Eng, R. H. K. Smith, S. M. \& Cherubin, C. (1984b). Inoculum effect of new $\beta$-lactam antibiotics on Pseudomonas aeruginosa. Antimicrobial Agents and Chemotherapy 26, 42-47.

Eng, R. H. K., Cherubin, C., Smith, S. M. \& Buccini, F. (1985). Inoculum effect of $\beta$-lactam antibiotics on Enterobacteriaceae. Antimicrobial Agents and Chemotherapy 28, 601-6.

Gootz, T. D. \& Sanders, C. C. (1983). Characterization of $\beta$-lactamase induction in Enterobacter Cloacae. Antimicrobial Agents and Chemotherapy 23, 91-7. 
